\title{
Riscos de Acidentes do Trabalho na Execução e Manutenções em Obras de Redes de Drenagem e Esgoto
}

\author{
Accident Risks in the Execution And Maintenance in Drainage \\ Works And Sewer Network \\ ${ }^{1}$ Cristina Catarina Machado(cristina@ sigaseguranca.com.br) \\ ${ }^{2}$ Admilson Pereira da Silva (admilsoncba@hotmail.com) \\ ${ }^{3}$ Jefferson dos Santos Marmello (jeffmarmello@yahoo.com.br) \\ ${ }^{4}$ Rafael Pedrollo de Paes (rafaeldepaes@gmail.com) \\ 1,2,3 , Graduandos em Engenharia Sanitária e Ambiental - UFMT \\ ${ }^{4}$ Professor Mestre do Departamento de Engenharia Sanitária e Ambiental - DESA/ UFMT
}

Recebido em dez,2014 Aceito em março 2015 Publicado em Junho 2015

\begin{abstract}
RESUMO - Este trabalho objetiva identificar, a partir de registros fotográficos, os riscos de acidentes do trabalho em obras de Redes de Drenagem e de Coleta de Esgotos (RDCE). O método empregado foi o estudo bibliográfico e os registros fotográficos de uma obra em Cuiabá/MT. Foi comparado o que preconiza a legislação vigente pertinente à matéria de segurança do trabalho, a Norma Regulamentadora- NR No 18 , e as dificuldades de implantação da mesma nas obras do setor de saneamento. A partir de pesquisas bibliográficas, foram identificados os possíveis efeitos e danos que os riscos de acidentes nas escavações podem gerar na integridade física e mental dos trabalhadores que laboram nesta área, bem como as deficiências de gestão administrativa que podem potencializar estes riscos e Programa de Condições e Meio Ambiente de Trabalho na Indústria da Construção Civil - PCMAT. A conclusão remete à necessidade de controle balizada na legislação trabalhista e nas recomendações. Esta conclusão se reflete nos números de acidentes do trabalho que é alarmante. Este trabalho poderá servir para consultas de profissionais das áreas afins e até mesmo como apoio para as empresas que tiverem interesse em diminuir o alto índice de acidentes e doenças causados nas atividades de saneamento.
\end{abstract}

Palavras chave: Segurança do trabalho; Saneamento, Obra.

\begin{abstract}
This paper aims to identify, from photographic records, the risks of occupational accidents in drainage networks works and Sewage Collection (RDCE).The method used was the bibliographical study and photographic records of a work in Cuiabá / MT. Was compared to that advocates the current legislation the committee work safety, the Regulatory Standard Number 18, and deployment difficulties of the same works in the sanitation sector. From literature searches, possible effects and damage that the risk of accidents in the excavations have been identified can lead to physical and mental integrity of workers who work in this area as well as the administrative management deficiencies that may enhance these risks, programs like PCMAT. The conclusion refers to the need to control marked out in labor legislation and recommendations. This conclusion is reflected in the number of work accidents is alarming. This work could serve to professional consultations related areas and even as support for companies that are interested in reducing the high rate of accidents and diseases caused to sanitation activities.
\end{abstract}

Keywords:Workplace safety; Sanitation; Engineering work.

\section{Introdução}

Até o início do século $\mathrm{XX}$ era grave o problema de saneamento nas metrópoles, causando epidemias que assolavam a população. Assim, em todo o Brasil, criaram-se redes de abastecimento de água e de esgoto sanitário por meio de um movimento nacional voltado para a realização de grandes obras de saneamento (SPERLING, 1996).

Conforme a Lei 11.445/2007 (BRASIL, 2007), que estabelece diretrizes nacionais para o saneamento básico, os municípios são os detentores dos serviços de saneamento básico em suas áreas de abrangência. $\mathrm{Na}$ tentativa de minimizar isto, acordos compartilham ou ainda 
concedem aos estados ou a iniciativa privada a responsabilidade desta matéria.

Nos contratos de concessão são previstos os cumprimentos dos Planos Diretores das cidades através de um cronograma de obras de infraestrutura prevendo o crescimento populacional e o desenvolvimento econômico e social (Lei 11.445, 2007). Porém os mesmos não prevêem no orçamento os investimentos necessários à minimização e controle dos riscos de acidentes e doenças do trabalho (SILVA, 2012).

Devido o alto grau de risco de acidentes de soterramento nas escavações das construções e manutenções nas redes de RDCE - Redes de Drenagem e Coleta de Esgoto, percebe-se a importância de pesquisas em alternativas de segurança do trabalho, no caso da Norma Regulamentadora NR 18 do Ministério do Trabalho (GONCALVES, 2008).

Sabe-se que na área de construção de redes de drenagem, há uma grande necessidade de qualificação de mão-deobra. A não qualificação dos operários acarreta em dificuldades em modernização do setor, pois gera desperdícios, proporciona baixa produtividade $\mathrm{e}$ contribui para má qualidade da obra, além disso, os acidentes estão intimamente ligados com a falta de formação técnica e profissional dos trabalhadores (SILVA, 1993).

Neste contexto, às vezes com ocorrências trágicas, os trabalhadores das obras de RDCE atuam com ações imediatas na resolução dos problemas que são atribuídos a eles, para a rápida restauração da execução das obras e do bem estar da população, como citado por Lopes (1998).

A prevenção de acidentes ou doenças será obtida quando houver consciência e aplicação de procedimentos eficazes como, por exemplo,os treinamentos específicos conforme a NR 18, a contratação de profissionais especializados em Segurança e Saúde do Trabalho - SST que fiscalizem as obras (SILVA, 1993).
As empresas ou órgãos do governo é que costumam ser responsabilizados diretamente pela ocorrência dos acidentes e doenças gerados pela falta de segurança do trabalho nas obras. Para tanto, os mesmos precisam estar munidos de conhecimentos e preparo para o desempenho da função (SILVA, 1993).

O presente artigo visa retratar o cenário das condições inseguras encontradas nas atividades de escavações de uma obra de drenagem de uma Construtora de Cuiabá/MT, e recomendar as principais medidas de prevenção de acordo com a NR-18 do Ministério do Trabalho e Emprego.

\section{Revisão Bibliográfica}

Devido ao grande consumo diário de água da população, tanto residencial como nas indústrias, há grande quantidade de esgoto gerado. Para a limpeza, conservação e tratamento das RDCE os trabalhadores são expostos a uma série de riscos, porém o que mais causa acidentes graves neste setor é o risco de soterramento, que ocorrem durante as escavações dessas redes (BOSSLE, 2015).

De acordo com Kulscar (2004), o grande problema nas obras de RDCE ocorre quando não são planejados corretamente, quando o sistema de esgotamento e as obras de drenagem não funcionam ou quando as galerias de concreto apresentam patologias em suas estruturas, provocando erosões no solo e, instabilidade nas construções e manutenções. Isso pode acarretar em problemas no passeio, nas edificações, equipamentos e infraestruturas existentes colocando em risco a vida dos trabalhadores e transeuntes, o que inclui pedestres, motoristas e moradores locais.

A definição do que trata a NR 18 ,que é uma das 36(trinta e seis) NR's - Normas Regulamentadoras de Segurança e Saúde no Trabalho, aprovadas pela lei 6.514 de 22 de dezembro de 1977 (BRASIL, 1977), que ditou a Portaria 3.214 de 8 de junho de 
1978 do MTE - Ministério do Trabalho e Emprego:

\section{NR 18 - CONDIÇÕES E MEIO AMBIENTE DE TRABALHO NA INDÚSTRIA DA CONSTRUÇÃO \\ 18.1 Objetivo e Campo de Aplicação \\ 18.1.1. Esta Norma Regulamentadora - NR estabelece diretrizes de ordem administrativa, de planejamento $e$ de organização, que objetivam a implementação de medidas de controle $e$ sistemas preventivos de segurança nos processos, nas condições e no meio ambiente de trabalho na Indústria da Construção. \\ ...18.1.2... \\ 18.1.3. É vedado o ingresso ou a permanência de trabalhadores no canteiro de obras, sem que estejam assegurados pelas medidas previstas nesta NR $e$ compativeis com a fase da obra. \\ 18.6 Escavações, Fundações e Desmonte de Rochas: \\ 18.6.1 A área de trabalho deve ser previamente limpa, devendo ser retirados ou escorados solidamente árvores, rochas, equipamentos, materiais e objetos de qualquer natureza, quando houver risco de comprometimento de sua estabilidade durante a execução de serviços.}

Os riscos de Acidentes conforme citado por Oda, Leila, Ávila, Suzana. et al.(1998):

"São todos os fatores que colocam em perigo o trabalhador ou afetam sua integridade física ou moral. São considerados como riscos geradores de acidentes: arranjo físico deficiente; máquinas e equipamentos sem proteção; ferramentas inadequadas ou defeituosas; choque elétrico; incêndio ou explosão; animais peçonhentos; armazenamento inadequado e soterramento. Arranjo físico deficiente, que é resultante de: prédios com área insuficiente; localização imprópria de máquinas e equipamentos; má arrumação e limpeza; sinalização incorreta ou inexistente; pisos fracos e/ou irregulares. Máquinas e equipamentos sem proteção, máquinas obsoletas; máquinas sem proteção em pontos de transmissão e de operação; comando de liga/desliga fora do alcance do operador; máquinas e equipamentos com defeitos ou inadequados; EPI inadequado ou não fornecido. Ferramentas inadequadas ou defeituosas - Ferramentas usadas de forma incorreta; falta de fornecimento de ferramentas adequadas; falta de manutenção. Armazenamento inadequado de inflamáveis e/ou gases; manipulação e transporte inadequado de produtos inflamáveis e perigosos".

Para efeitos legais, também devemos seguir a definição de acidente do trabalho e de doença profissional, apregoados pela Previdência Social, estabelecidos nos artigos 19 e 20 da Lei Federal 8.213, de 24 de julho de 1991 (BRASIL, 1991):

Acidente do trabalho é o que ocorre pelo exercício do trabalho a serviço da empresa ou pelo exercício do trabalho dos segurados referidos no inciso VII do art. 11 desta Lei, provocando lesão corporal ou perturbação funcional que cause a morte ou a perda ou a redução, permanente ou temporária, da capacidade para trabalho.

Doença profissional, assim entendida a produzida ou desencadeada pelo exercício do trabalho peculiar a determinada atividade e constante da respectiva relação elaborada pelo Ministério do Trabalho e da Previdência Social.

As atividades nas RDCE são consideradas tão prejudiciais que a NR n. ${ }^{\circ} 15$ do MTE, que trata sobre Atividades e Operações Insalubres, prevê insalubridade em grau máximo para o trabalho ou operação em contato permanente com esgotos, determinando o pagamento de $40 \%$ de adicional sobre o salário, o mais alto percentual determinado pela norma.

Segundo Araújo (2008), somente o pagamento do adicional não resolve $o$ problema da exposição do trabalhador e das doenças às quais ele pode se expor. É preciso tornar esta atividade mais adequada do ponto de vista da Saúde e Segurança do Trabalho.

Segundo Bossle (2015), o estado de Mato Grosso, possuía uma população de 596.291 empregados ativos em 2011, sendo que no setor de "Água, Esgoto e Resíduos" existia 2.412 trabalhadores e neste cenário ocorreram 2 (duas mortes). Relacionando com o seguimento da 
"Indústria da Construção", com seus mais de 90.000 trabalhadores ativos no mesmo ano em Mato Grosso, que apresentou 18 (dezoito) óbitos, comparativamente a Indústria da Construção que teve ainda assim possui um de mortalidade maior do que o da Construção, isto é, enquanto que na Indústria da Construção é de 19,67 no setor de "Água, Esgoto e Resíduos" é de 82,97 para cada grupo de 100.000 .

O problema é mais grave quando observamos gestores que mesmo com a coresponsabilidade desenhada, continuam tratando de forma diferente os regidos pela CLT dos regidos pela lei 8112/90, no que tange a prevenção e as correções necessárias a minimização ou eliminação dos riscos que poderão promover acidentes ou danos a saúde dos colaboradores (SILVA, 1993).

De acordo com o Ministério da Previdência e Assistência Social - MPAS (2012), o alto potencial de geração de acidentes graves em atividades do setor de saneamento, estão diretamente relacionadas com o baixo investimento na mão-de-obra e a conscientização das pessoas que gerenciam as empresas e órgãos públicos.

\section{Objetivos e Métodos}

O objeto de estudo desta pesquisa é o reconhecimento dos riscos de acidentes durante as escavações em uma obra de RDCE no município de Cuiabá/MT e a verificação comparativa destas atividades com o disposto no item 18.6 da Norma Regulamentadora da NR18 do Ministério do Trabalho.

Os métodos para o reconhecimento dos riscos enfrentados pelos trabalhadores e a comparação com a NR18 seguiram as seguintes etapas:

1 - Foi utilizado para subsidiar as análises dos riscos de acidentes que os trabalhadores enfrentam, o acompanhamento de atividades de uma Construtora que realizava a obra de Drenagem em uma região da periferia do Município de Cuiabá/MT (SIGA, 2013);
2 - Visualização do PCMAT da Obra;

3 - Geração de uma tabela correlacionando as obrigações determinadas pela NR18 no item 18.6 - Escavações, Fundações e Desmonte de Rochas, com os riscos evidenciados em análise qualitativa da obra através dos registros fotográficos;

4 - Indicar recomendações das principais medidas de prevenção e medidas administrativas para melhorar as condições laborais do setor de drenagem e redes de esgoto.

\section{Resultados e Discussões}

Para os resultados, serão realizadas as análises comparativas onde foram verificados os dados obtidos pelos registros fotográficos e as informações sobre os diversos os graus de exigências da NR18 para as atividades de Escavações, especificamente. Os itens comparativos foram selecionados, levando em conta o que determina a norma e a complexidade dos trabalhos nas RDCE.

Figura 1 - Riscos de acidente nas obras de construção de RDCE.

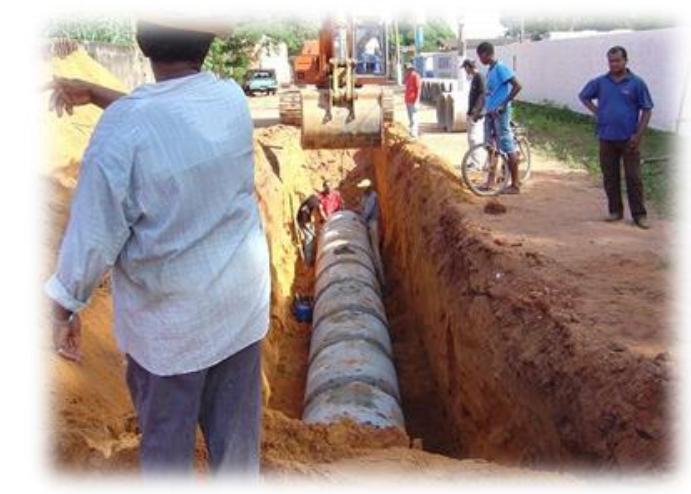

Fonte: SIGA, 2013.

Tabelas de reconhecimento dos riscos de acidentes e a comparação com o dispositivo legal determinado na NR $18 \mathrm{em}$ seu item 18.6: Escavações, Fundações e Desmonte de Rochas com a obra de construção e manutenção de RDCE: 
Tabela 1 - Comparativo NR18 e atividades em Campo. Fonte: Elaboração Própria.

Definições da NR18 em seu item 18.6 e seus subitens (MTE, 1978)

18.6.1 A área de trabalho deve ser previamente limpa, devendo ser retirados ou escorados solidamente árvores, rochas, equipamentos, materiais e objetos de qualquer natureza, quando houver risco de comprometimento de sua estabilidade durante a execução de serviços.

18.6.2;18.6.3;18.6.4; 18.6.5 Os taludes instáveis das escavações com profundidade superior a $1,25 \mathrm{~m}$ (um metro e vinte e cinco centímetros) devem ter sua estabilidade garantida por meio de estruturas dimensionadas para este fim.

18.6.6-18.6.10...

18.6.11 As escavações realizadas em vias públicas ou canteiros de obras devem ter sinalização de advertência, inclusive noturna, e barreira de isolamento em todo o seu perímetro.
Verificação do cumprimento norma em uma Obra de RDCE de Cuiabá/MT

Na Figura 1 estão apresentadas algumas das condições degradantes nas obras de RDCE. Em evidência, o não uso dos EPI's - Equipamentos de Proteção Individual (NR06), o risco de soterramento, a falta de isolamento de obra, a falta de proteção na Retroescavadeira e o afastamento adequado dos trabalhadores e o risco de tombamento da máquina sobre os operários. Não há proteções, nem escoras nas laterais das escavações.

Não há sinalizações descumprindo item 18.6.11.

Conclusão parcial: Itens da NR 18 não foram atendidos.

Tabela 2 - Comparativo NR18 e atividades em campo.Fonte: Elaboração própria.

\section{Definições da NR18 em seu item 18.6 e seus subitens}

18.6.6 Para elaboração do projeto e execução das escavações a céu aberto, serão observadas as condições exigidas na NBR 9061/85 - Segurança de Escavação a Céu Aberto da ABNT.

18.6.7 As escavações com mais de $1,25 \mathrm{~m}$ (um metro e vinte e cinco centímetros) de profundidade devem dispor de escadas ou rampas, colocadas próximas aos postos de trabalho, a fim de permitir, em caso de emergência, a saída rápida dos trabalhadores, independentemente do previsto no subitem 18.6.5.

18.6.8 Os materiais retirados da escavação devem ser depositados a uma distância superior à metade daprofundidade, medida a partir da borda do talude.
Verificação do cumprimento norma em uma Obra de RDCE de Cuiabá/MT

$\mathrm{Na}$ Figura 2 durante a escavação com máquina retroescavadeira para rede RDCE, o trabalhador esta exposto ao sol, ao calor e sua condição de trabalho esta insegura, pois o mesmo poderá sofrer quedas.

$\mathrm{O}$ empregador sequer planejou conforme exige a norma uma passarela móvel de apoio para o trabalhador atravessar a vala.

De acordo com Araújo (2008), as áreas de escavação devem ser sinalizadas protegidas para evitar posturas inadequadas por longas jornadas de trabalho.

Conclusão parcial: Itens da NR 18 não foram atendidos.
Figura 2 - Evidência de Trabalhador em atividade à céu aberto.

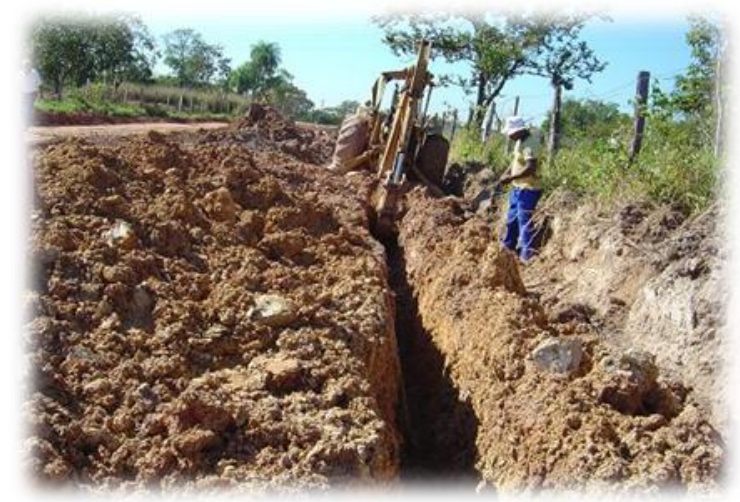

Fonte: SIGA, 2013.
Figura 3 - Vala com profundidade maior que $1,8 \mathrm{~m}$, sem observância das normas de Segurança.

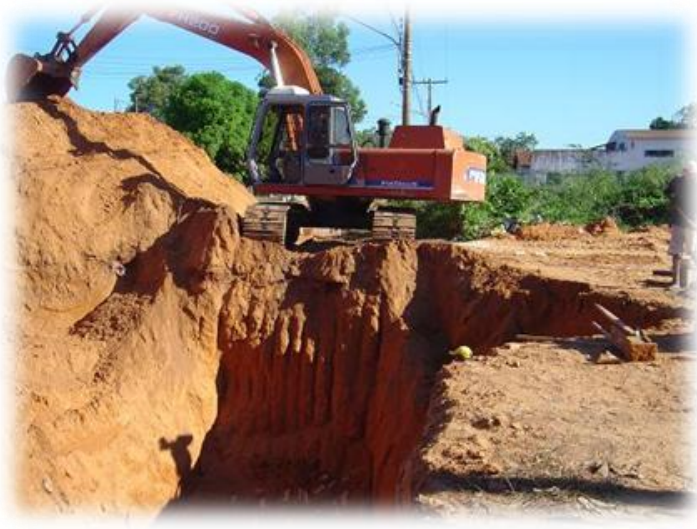

Fonte: SIGA, 2013 
Figura 4 - Vala com profundidade maior que $1,8 \mathrm{~m}$, sem observância das normas de Segurança.

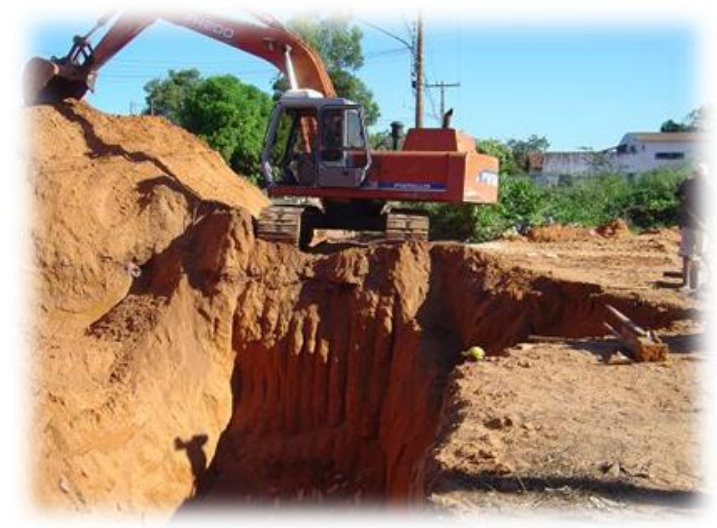

Fonte: SIGA, 2013.
Figura 5 - Colocação de dutos sem observância das normas de Segurança

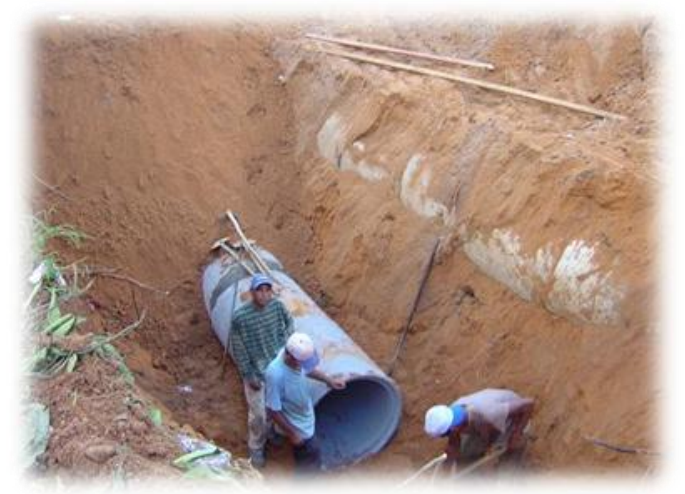

Fonte: SIGA, 2013

Tabela 3- Comparativo NR18 e Atividades de construção de RDCE. Fonte: Elaboração própria.

Definições da NR18 em seu item 18.6 e seus subitens

18.6.5 Os taludes instáveis das escavações com profundidade superior a 1,25m (um metro e vinte e cinco centímetros) devem ter sua estabilidade garantida por meio de estruturas dimensionadas para este fim.

...18.6.6...

18.6.7 As escavações com mais de 1,25m (um metro e vinte e cinco centímetros) de profundidade devem dispor de escadas ou rampas, colocadas próximas aos postos de trabalho, a fim de permitir, em caso de emergência, a saída rápida dos trabalhadores, independentemente do previsto no subitem 18.6.8 Os materiais retirados da escavação devem ser depositados a uma distância superior à metade da profundidade, medida a partir da borda do talude.

18.6.9 Os taludes com altura superior a 1,75m (um metro $e$ setenta e cinco centímetros) devem ter estabilidade garantida.

18.6.20.1 Toda escavação somente pode ser iniciada com a liberação e autorização do Engenheiro responsável pela

execução da fundação, atendendo o disposto na NBR 6122:2010 ou alterações posteriores. (Incluído pela Portaria MTE n. ${ }^{\circ}$ 644, de 9 de maio de 2013);

18.6.21 Os tubulões a céu aberto devem ser encamisados, exceto quando houver projeto elaborado por profissional legalmente habilitado que dispense o encamisamento, devendo atender os seguintes requisitos: (Alterado pela Portaria MTE n. ${ }^{\circ}$ 644, de 9 de maio de 2013).

a) sondagem ou estudo geotécnico local, para profundidade superior a 3metros;

b) todas as medidas de proteção coletiva e individual exigidas para a atividade devem estar descritas no Programa de Condições e Meio Ambiente de Trabalho na Indústria da Construção - PCMAT, bem como plano de resgate e remoção em caso de acidente, modelo de check list a ser aplicado diariamente, modelo de programa de treinamento destinado aos envolvidos na atividade contendo as atividades operacionais, de resgate e noções de primeiros socorros, com carga horária mínima de 8 horas;

c) as ocorrências e as atividades sequenciais das escavações dos tubulões a céu aberto devem ser registradas diariamente em livro próprio pelo engenheiro responsável;

d) é proibido o trabalho simultâneo em bases alargadas em tubulões adjacentes, sejam estes trabalhos de escavação e/ou de concretagem; e) é proibida a abertura simultânea de bases tangentes.
Verificação do cumprimento norma em uma Obra de RDCE de Cuiabá/MT

A instabilidade do talude que esta aparente na figura 3 deveria ter sido prevenida antes do inicio da obra e este procedimento estabelecido pela norma NR18, que trata o item 18.6.5 deve ser seguido por todas as empresas que realizam escavações. Na figura 3 vê-se que não há cumprimento do item 18.6.7, pois os operários estão sem escadas ou rampas, e uma profundidade superior a 1,25, sendo que um deles inclusive já esta dentro da vala sem nenhuma proteção.

Conclusão parcial: Itens da NR 18 não foram atendidos.

Os trabalhadores das Figuras 3 e 4, ao serem questionados afirmam não possuírem treinamento algum para execução das tarefas.

Não receberam EPI's, estão trabalhando a Céu aberto sem proteção.

A empresa contratou a elaboração do PCMAT apenas ao final da obra, ou seja, não foram previstas medidas mitigadoras de riscos de acidentes.

$\mathrm{O}$ risco de soterramento e deslizamento dos taludes esta iminente.

Para o içamento dos tubulões ou manilhas não há procedimentos de segurança, as amarrações são inadequadas e os operários permanecem na vala durante a descida do equipamento de guindar com os tubulões e ou manilhas.

Conclusão parcial: Itens da NR 18 não foram atendidos. 
Conforme cita Araújo (2008), as situações acima elencadas podem ter como base os seguintes fatores: a) Erro de imputar aos municípios a responsabilidade por investimentos em RDCE - Redes de Drenagem e Coleta de Esgoto sem reter receita suficiente para tais obras, por causo do sistema tributário que destina eles a menor parcela da arrecadação fracionada também a estados e federação. b) Por ter uma parte significativa de obras de menor porte, as empresas contratadas e equipes da prefeitura, tem em sua maioria corpo técnico com pouca estrutura de trabalho e sobre certos aspectos com baixa formação. b) Gestores e políticos que desconhecem ou omitem assuntos legais da esfera trabalhista, evidenciado nos contratos com informações simplórias quanto ao assunto segurança do trabalho em obras.

\section{Recomendações}

A proposta é que os gestores das atividades e obras nas RDCE possuam alternativas simples e objetivas para atendimento às normas regulamentadoras do MTE. Para contribuir com as melhorarias das condições laborais dos profissionais que atuam no dia-a-dia em serviços de grande desgaste, como obras de saneamento básico, a fim de haver mitigação dos agravos à saúde e à segurança no trabalho, os são recomendadas as seguintes propostas:

1. Capacitação da equipe técnica com assuntos relacionados a segurança e saúde do trabalho, bem como aspectos relacionados a liderança e responsabilidade;

2. Indicação de um Programa de Treinamentos Específicos aos trabalhadores conforme NR18 da Portaria 3.214/78;

3. Elaborar projeto de construção antes da execução, e este servir de base a elaboração do PCMAT, conforme definições contidas na NR18 da Portaria 3.214/78;

4. Promover políticas de planejamento das tarefas, antes da efetiva execução;
5. Aquisição de EPC - Equipamentos de Proteção Coletiva e EPI - Equipamentos de Proteção Individual, conforme preconiza NR-6 e normas técnicas;

6. Criar e implantar as PT's - Permissões para Trabalho em atividade padrão de escavação (Elaborar um documento padrão onde o supervisor sempre autorizará e se responsabilizara pelas escavações antes de serem iniciadas);

7. Criação, implantação de APR- Análise Preliminar de Riscos Exemplo: Criar uma POP sobre critérios, normas e rotinas para a escavação de taludes para implantação ou manutenção das RDCE, identificando alturas apropriadas de taludes, tipos de escoramento, quantidade mínima de trabalhadores para execução por metro quadrado escavado, estabelecimento de distância mínima entre maquinas (retroescavadeira e pessoal realizando escavação manual e por fim uma definição de método de salvamento e resgate em caso de acidente);

8. Elaborar treinamentos voltados a prevenção, primeiros socorros e de responsabilidade social em suas atividades, e;

9. Elaboração programas de prevenção e saúde, específicos às atividades desenvolvidas e exames médicos compatíveis com elas;

10. Contratar empresas especializadas ou profissionais qualificados na área de Segurança do Trabalho para execução e controle das recomendações acima.

\section{Conclusão}

Todas as infraestruturas de tratamento e distribuição de água de abastecimento e de drenagem ou esgotamento sanitário devem possuir Programas de Segurança e Saúde. Esses Programas são baseados na identificação e reconhecimento dos principais riscos ocupacionais que estão expostos os trabalhadores, comunidade e transeuntes, bem como nas medidas de prevenção a serem adotadas em cada situação. 
As medidas de prevenção servem de suporte para as auditorias de controle efetuadas nos locais de trabalho e a legislação específica do país (ARAÚJO, 2008).

Ainda que haja esses programas, existe a necessidade de desenvolver uma campanha conjunta para que os documentos de segurança e saúde não fiquem arquivados para simples atendimento de legislação, sem serem aplicados em obra. O programa de sensibilização é conjunto, e envolve todos os grupos: governo, empresas e sindicatos.

Com a identificação específica dos riscos predominantemente evidenciados neste instrumento de pesquisa, conclui-se que as condições laborais dos profissionais do saneamento ainda são muito precárias. Dos 23 (vinte e três) subitens do item NR18.6, definimos 10 (dez) como principais nas tabelas de discussão, e destes avaliados, nenhum conseguiu atender aos preceitos da norma, ou seja, a obra que utilizamos como amostra para o estudo encontra-se $100 \%$ irregular.

As recomendações apresentadas neste artigo farão com que o mesmo sirva para consultas de profissionais das áreas afins e como apoio para as empresas que tiverem interesse em diminuir o alto índice de acidentes nas escavações causados nas atividades de saneamento.

\section{Agradecimentos}

Agradecemos o professor Rafael Paes nos apoiou e orientou para o desenvolvimento deste trabalho. À respeitosa comissão de editores e a banca examinadora dos artigos, nossa eterna gratidão pelo respeito e oportunidade de divulgar nosso artigo na Revista E\&S.

\section{Referências}

ARAUJO, G. M. de. Normas Regulamentadoras Comentadas. Legislação de Segurança e Saúde no Trabalho. Volume 1e 2. $8^{a}$ Edição. Rio de
Janeiro/RJ: Gerenciamento Verde Editora e Livraria Virtual, 2008.

BOSSLE, Daniela. Anuário Brasileiro de Proteção. Revista Proteção. Edição 20. Novo Hamburgo/RS. 2015.

KULCSAR NETO, F. Espaços Confinados são Causa de Acidentes de Trabalho no Brasil. 3. ${ }^{a}$ edição. São Paulo/SP: FUNDACENTRO, 2004.

Lei 6.514 de 22 de dezembro de 1977 Lei do Governo Federal. Disponível em: <http://www010.dataprev.gov.br/sislex/pa ginas/42/1977/6514.htm> Acesso em 05 de fevereiro de 2015.

Lei 8.213 de 24 de julho de 1991 - Lei da Previdência. Disponível em: <http://www81.dataprev.gov.br/sislex/ paginas/42/1991/8213.htm.> Acesso em: 20 de Agosto 2014.

Lei 11.445 de 5 de janeiro de 2007 Presidência da República Casa Civil - Disponível em < http://www010.dataprev.gov.br/sislex/pagi nas/42/1991/8213.htm> Acesso em 01 de fevereiro de 2015.

LOPES, L. F. P. Citação em Gestão da CIPA 98/99, Regimento Interno. Porto Alegre/RS, 1998.

MPAS. Ministério da Previdência e Assistência Social. Relação Anual de Informações Sociais, 2012.

BRASIL, MTE. Ministério do Trabalho e Emprego. Portaria SITN ${ }^{\circ} 25$ de 15 de OUT 2001. NR 06. Equipamentos de Proteção Individual - EPI, 2014.

MTE. Ministério do Trabalho e Emprego. Portaria No 25 de 29 de DEZ 1994. NR 09. Programas de Prevenção de Riscos Ambientais, 2014.

MTE. Ministério do Trabalho e Emprego. Alterada pela Portaria SIT No 82 de 01 de JUN 2004. NR 11 - Transporte, 
Movimentação, Armazenagem e Manuseio de Materiais, 2014.

,MTE. Ministério do Trabalho e Emprego. Alterada pela Portaria MTE N ${ }^{\circ}$ 1297 de 13 de AGOSTO 2004. NR 15. Atividades e Operações Insalubres, 2014.

, MTE. Ministério do Trabalho e Emprego. Alterada pela Portaria MTE N ${ }^{\circ}$ 644 de 09 de MAIO 2013. NR 18.Condições e Meio Ambiente de Trabalho na Indústria da Construção, 2014.

MTE. Ministério do Trabalho e Emprego. NR33. Segurança e saúde nos trabalhos em espaço confinado. Publicada no DOU $\mathrm{N}^{\circ}$ 247, DE 27/12/2006, SEÇÃO 1, p. 144. Brasília, 2006.

PROTEÇÃO: Revista mensal de saúde e segurança do trabalho. Reportagem: Marla Cardoso. Riscos em Esgoto. Novo Hamburgo/RS: MPF publicações, n.250253 Out-Dez. 2012.

SAAD, E. G. (Superv.) Introdução à Engenharia de Segurança do Trabalho. São Paulo: FUNDACENTRO, 1981.

SIGA. Saúde, Segurança e Meio Ambiente do Trabalho. Acervo Técnico Próprio. PPRA - Programa de Prevenção de Riscos Ambientais 2013 - Disponível em Site: www.sigaseguranca.com.br

SILVA, Jason Alves da. Acidentes do Trabalho na Construção Civil. Revista CIPA. São Paulo.n.167 p.48, 1993.

SPERLING, M. V. Introdução à qualidade das águas e tratamento de esgoto. Belo Horizonte: Departamento de Engenharia Sanitária e Ambiental, Universidade Federal de Minas Gerais, 3 ed., 452p. 2005. 